\title{
A Noble Conductivity Studies and Characterizations of PVA-Orthophosphoric-Filter Paper Electrolytes
}

\author{
Lawal Sa'adu ${ }^{1}$, M. A. Hashim ${ }^{1} \&$ Masbudi bin Baharuddin ${ }^{1}$ \\ ${ }^{1}$ Faculty of Science and Technology, Universiti Sains Islam Malaysia (USIM), Malaysia \\ Correspondence: Lawal Sa'adu, Faculty of Science and Technology, Universiti Sains Islam Malaysia (USIM), \\ Bandar Baru Nilai, Negeri Sembilan 71800, Malaysia. E-mail: lawals2004@gmail.com
}

Received: June 24, 2014 Accepted: July 20, 2014 Online Published: July 28, 2014

doi:10.5539/jmsr.v3n4p1 URL: http://dx.doi.org/10.5539/jmsr.v3n4p1

\begin{abstract}
The nobility of solid polymer electrolyte (SPEs) has made them a subject of interest, especially in the arena of science and technology, and most importantly as they are used as separators in industries and by researchers for the assembly of some "few battery types" and supercapacitors. This paper, highlights the nobility of the hybrid solid polymer electrolyte (HSPE), particularly at room temperature such that, it can be used as an electrolyte as well as a separator in supercapacitor fabrication. The hybrid SPEs were produced from the composition of polyvinyl alcohol (PVA) and Phosphoric acid $\left(\mathrm{H}_{3} \mathrm{PO}_{4}\right)$, where the PVA samples were kept constant while the phosphoric acid concentration was varied at $0,10,20,30,40,50,60$, and $70 \mathrm{wt} \%$. XRD results show that, the crystallinity decreases as the acid concentration increases and consequently, there is an enhancement in the amorphicity of the samples responsible for the process of ion transport. This characteristic behavior was confirmed by the analysis of the differential scanning calorimetry results. FESEM result pictured the entangling nature of the combined samples. High conductivity of $1.67 \times 10^{-3 .} \mathrm{Scm}^{-1}$ was recorded for the HSPE at the composition of $70: 30 \mathrm{wt} . \%$. It was also noticed that, the bulk modulus, $R_{\mathrm{b}}$ of the HSPE (5.73 $\Omega$ ) at the aforementioned composition decreases with the increase in concentration.
\end{abstract}

Keywords: hybrid solid polymer electrolyte (HSPE), polyvinyl alcohol (PVA), phosphoric acid $\left(\mathrm{H}_{3} \mathrm{PO}_{4}\right)$, Electrochemical Impedance Spectroscopy (EIS). Differential Scanning Calorimetry (DSC) Analysis

\section{Introduction}

The invention of polymer electrolyte by Fenton and co-workers (Gu et al., 2000; Kumar \& Sundari, 2010; Zhang et al., 2006; Yang, 2004; Ragavendran et al., 2004; Tripath et al., 2012; Ulaganathan et al., 2012; Kuo et al., 2013; Yang et al., 2013; Noor et al., 2010) and Armand (Ragavendran et al., 2004; Zhang et al., 2006) marked exactly three decades (1973) in the year 2013, and ever since then, there has been continuous breakthrough in the research of polymer electrolyte. Three classifications of polymer electrolyte systems have been identified recently. These include, (i) Polyelectrolytes (PEs): - which have independent ion-generating groups chemically bond to the macromolecular chain and presence of counter-ion in order to maintain the electroneutrality of the salt. These types of polymers have low conductivity of about $10^{-10}-10^{-15} \mathrm{Scm}^{-1}$ in dry conditions, but in the presence of dielectric solvent such as water, there conductivities do improve (Ulaganathan et al., 2012). (ii) Solvent Swollen Polymer Electrolytes (SSPE): - In SSPE, solvents, both aqueous and non-aqueous swells the host polymer live PVA. So, the dopant ionic solutes such as $\mathrm{H}_{3} \mathrm{PO}_{4}$ is hosted in the swollen lattice thereby permitting the motion of ions in the solvent swollen region of the polymer host. Their conductivity depends on the concentration of the solvent in the region that is being swollen (Ulaganathan et al., 2012). And lastly (iii) the Solvent Free Polymer Electrolytes (SFPE): These are polymer salt complex, which is formed by complexes between salts of alkali metals and polymer containing solvating hetroatoms, example; O, S and N (Ulaganathan et al., 2012). The complexation between poly ethylene oxide (PEO) and alkali metal salts is a good example of SFPE. SFPE are sub-classified into three also. They are; (a) Solid Polymer Electrolytes (SPEs), (b) Gel Polymer Electrolytes (GPEs), and (c) Composite polymer electrolytes (CPEs) (Kuo et al., 2013; Tripath et al., 2012). GPEs can be simply regarded as plasticizers incorporated polymer-salt complex (Ulaganathan et al., 2012). They are therefore consisted of a liquid electrolytes immobilized in a polymer matrix (Hashmi, 2013a) and exhibits high ionic conductivity $\left(10^{-3}\right.$ to $10^{-4}$ $\mathrm{Scm}^{-1}$ at ambient temperature) and can be obtained by either loading of a liquid electrolyte in a microporous matrix or by increasing the viscosity of a liquid electrolyte through the addition of a soluble polymer until gel consistency 
is achieved or by mixing a liquid electrolyte with monomers of relatively low molecular weight, then curing the mixture by other means, such as UV polymerization, thermal polymerization and electron beam radiation polymerization. They are criticized for having weak mechanical strength and poor interracial properties (Qiu et al., 2004; Hashmi, 2013b). In CPEs, they are normally prepared by addition of high surface inorganic filters like $\mathrm{SiO}_{2}$, $\mathrm{MgO}, \mathrm{TiO}_{2}$ and alike so as to improve the mechanical strength and stiffness of the complex systems (Ulaganathan et al., 2012). Furthermore, SPE is thin films with ionic conductivity when especially an alkali, salt dissolves in polymer matrix. SPE have drawn great attention in the development of science and technology of lithium secondary batteries. SPEs have several advantages over liquid, gel or even composite electrolytes in that, it has process ability, flexibility, light weight, elasticity and transparency (Zhang et al., 2006), desirable shape moldability, being free from leakage, mechanical strength, better stability especially in high temperature, and high specific energy and power (Lim et al., 2012). Furthermore, use of use of solid polymer electrolyte can negate the need for a separator and be amendable to low cast manufacturing technologies (Qiu et al., 2004). Some of the applications of SPE are in Batteries, fuel cell, supercapacitors and other electrochemical devices (Sawada et al., 2000) and other electrochemical devices (Sotta et al., 2010).

Works published particularly on the hybrid polymer electrolyte characterizations are quite minimal. Most of the publications focused on the characterizations of pure solid polymer electrolyte such as those in Prajapati et al. (2010) and Ahmad Khiar and Arof (2010). It's in light of the above that, this paper tries to offer a step by step approach on the conductivity studies of the this hybrid polymer so as to determine the specialties peculiar to it, in comparison with the pure solid polymer electrolyte and to ascertain the suitability composition for the usage in the supercapacitor fabrication which is the main target of our future work. Hence, careful measures have been put in place to ensure that, every detail characteristic of the active materials, especially of the PVA (its molecular weight and its percentage hydrolysis), the type of the acid used and even the filter paper brand were taken into considerations

\section{Experimental}

\subsection{Preparation of the Composite PVA Electrolytes}

The hybrid solid polymer electrolytes (HSPEs) experimental preparation was discussed elsewhere by us, in Hashim et al. (2012), Hashim et al. (2014) and by Jiang et al. (2013). We also show how effective they are when used as separators and electrolytes in the supercapacitor fabrication. The HSPEs were prepared using the active materials comprise of $\mathrm{H}_{3} \mathrm{PO}_{4}$ and PVA. The $\mathrm{H}_{3} \mathrm{PO}_{4}$ functions as an ionic liquid, while PVA acts as a polymeric matrix, allowing ionic transport while simultaneously functioning as a separator between the electrodes of the supercapacitor. On the other hand, $\mathrm{H}_{3} \mathrm{PO}_{4}(>85 \mathrm{wt} . \%$ in water, molar mass of $98.00 \mathrm{~g} / \mathrm{mol}$, product, number of 1502-80) was obtained in aqueous form from R \& M marketing, Essex, UK brand, while the PVA (molecular weight; 89,000-98,000, 99+\% hydrolyzed) was obtained from Sigma Aldrich. Both $\mathrm{H}_{3} \mathrm{PO}_{4}$ and $\mathrm{PVA}$ were used as-received without further treatment or purification. An aqueous solution of PVA is prepared by combining PVA with distilled water in the ratio of 1:10 by volume. This solution is mechanically agitated by magnetic stirring at $60{ }^{\circ} \mathrm{C}$ for five hours to thoroughly dissolve the PVA in the distilled water. $\mathrm{H}_{3} \mathrm{PO}_{4}$ was then mixed with the PVA aqueous solution in the ratio of 100:0, 90:10, 80:20, 70:30, 60:40, 50:50, 40:60 and 30:70 wt. \% for the HSPE to be obtained. (This mixture has been summarized in Table 1). The mixing is done in a drop-wise manner with magnetic stirring at $60{ }^{\circ} \mathrm{C}$ for about one hour until it completely turns to homogeneous solution.

The mixture is then allowed to cool down to an ambient temperature. The resulting homogeneous solution of $\mathrm{PVA} / \mathrm{H}_{3} \mathrm{PO}_{4}$ is cast over a plastic Petri dish. Prior to this, the Petri dish was scraped off the dust using a tissue soaked in acetone. The $\mathrm{PVA} / \mathrm{H}_{3} \mathrm{PO}_{4}$ solution solidifies onto the Petri dish and upon curing for about $3-4$ weeks at room temperature. The longer curing period is connected to its high molecular weight and consequently more hydrolyzed. Prior to that also, a cellulose filter paper (Whatman brand) is cut into a $6 \mathrm{~cm} \times 5.5 \mathrm{~cm}$ and soaked in a segment of the aforementioned solution. The solid layer was easily peeled off from the Petri dish after it dries as a freestanding layer as shown in Figure 1. The resulting polymer film was then put in the plastic bags for safe keeping, and to avoid contamination from surrounding, for further property analysis

\section{Result and Discussion}

\subsection{Conductivity and Chemical Composition Analysis}

The Conductivity measurements of the different percentage ratio of $\mathrm{PVA}-\mathrm{H}_{3} \mathrm{PO}_{4}$ of $\mathrm{HSPE}$ films were carried out using an impedance method that was highlighted by Ahmad Khiar and Arof (2010). The hybrid solid polymer films were sandwiched between a stainless steel, ion-blocking liked measuring device (otherwise known as a probe), each of surface area $2 \mathrm{~cm}^{2}$ in radio, in a spring-loaded glass holder. The impedance measurements were carried out by using Electrochemical Impedance Spectroscopy (EIS) testing machine named HIOKI 3532-50 LCR 
Hi-Tester which was interfaced to a computer. The frequency range of the device was $50 \mathrm{~Hz}-1 \mathrm{MHz}$, and simultaneously calculating both real and imaginary impedance.

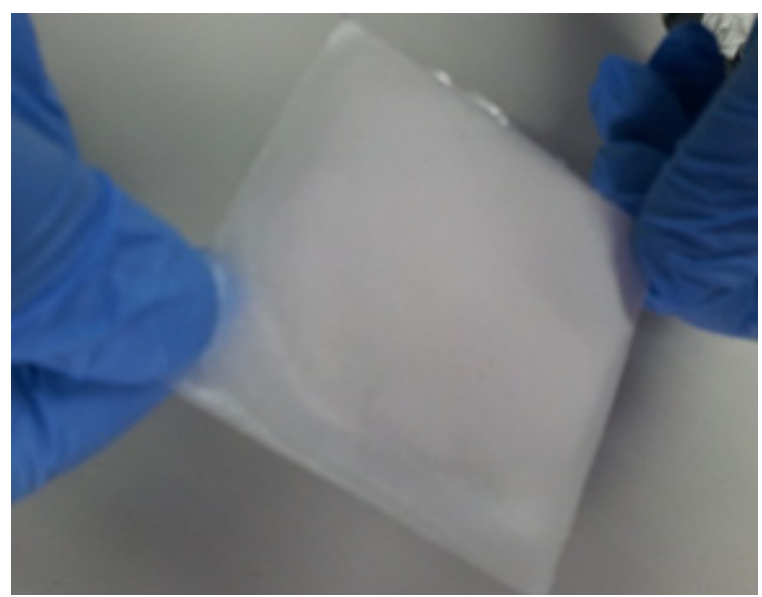

Figure 1. Showing a prepared HSPE

Table 1. Table Showing the Overall Formation of the HSPE Preparation

\begin{tabular}{lccc}
\hline Coding & $\begin{array}{c}\text { Measured Quantity PVA } \\
\text { in Distilled Water }(\mathrm{g})\end{array}$ & $\begin{array}{c}\text { Measured Quantity } \\
\text { of } \mathrm{H}_{3} \mathrm{PO}_{4}(\mathrm{~g})\end{array}$ & $\begin{array}{c}\text { Ratio of PVA to } \\
\mathrm{H}_{3} \mathrm{PO}_{4}\end{array}$ \\
\hline $\mathrm{H} 0$ & 2 & 0 & $100: 0$ \\
$\mathrm{H} 10$ & 2 & 0.22 & $90: 10$ \\
$\mathrm{H} 20$ & 2 & 0.50 & $80: 20$ \\
$\mathrm{H} 30$ & 2 & 0.86 & $70: 30$ \\
$\mathrm{H} 40$ & 2 & 1.33 & $60: 40$ \\
$\mathrm{H} 50$ & 2 & 2.00 & $50: 50$ \\
$\mathrm{H} 60$ & 2 & 3.00 & $40: 60$ \\
$\mathrm{H} 70$ & 2 & 4.67 & $30: 70$ \\
\hline
\end{tabular}

The sample exhibits Debye characteristics, and then the plots of the negative imaginary impedance versus the real impedance on the graph should be able to display a semicircle-like shape (Ahmad Khiar \& Arof, 2010). From the Equation 1, we calculated the electrical conductivity of the samples;

$$
\sigma=\frac{l}{R_{b} A}
$$

Where $\sigma$ is the conductivity $l, R_{b}$ and $A$ are respectively the thickness, bulk modulus and area of the samples. The thickness of the sample was measured twice at different positions of the polymer films and an average was taken using digital micrometer.

Figure 2 (a-h) shows impedance plots of a sample of the HSPE containing $0,10,20,30,40,50,60$, and $70 \mathrm{wt} . \%$ ratio of the $\mathrm{H}_{3} \mathrm{PO}_{4}$ at room temperatures respectively. The manifestation of semicircle in the $10 \mathrm{wt}$. \%, might be as a result of the presence of the immobile polymer chain that could be found in the filter paper itself. In this case also, it was observed that, the $R_{\mathrm{b}}$ value decreases with the increase in concentration. The calculated values of the $R_{\mathrm{b}}$ are $1.15 \times 10^{9}, 1.15 \times 10^{6}, 1.00 \times 10^{6}, 1.50 \times 10^{3}, 2.10 \times 10^{3}, 4.30 \times 10^{1}, 7.37 \times 10^{1}$ and $5.73 \Omega$ for $0,10,20,30,40,50$, 60 , and 70 wt. \% ratio of the $\mathrm{H}_{3} \mathrm{PO}_{4}$ respectively. Moreover, Table 1 summarizes the relationship between the acid concentration and the polymer matrix. It was further deduced from the table that, the thickness on each sample, had some impact on the conductivity of the samples. Hence, while the calculated bulk moduli of the HSPE are found to be promising, the thickness of the sample hinders its conductivity. However, in terms of use as separator in 
supercapacitor, the use of HSPE proved to be more acceptable and better as it has been reported by us in (Hashim et al., 2014). Furthermore, the highest conductivity was noticed for the HSPE was $1.67 \times 10^{-3} \mathrm{Scm}^{-1}$ when the $\mathrm{H}_{3} \mathrm{PO}_{4}$ was increased to $70 \mathrm{wt}$. \% and the lowest conductivity was noticed at $2.25 \times 10^{-11} \mathrm{Scm}^{-1}$ when the $\mathrm{H}_{3} \mathrm{PO}_{4}$ percentage was nil.
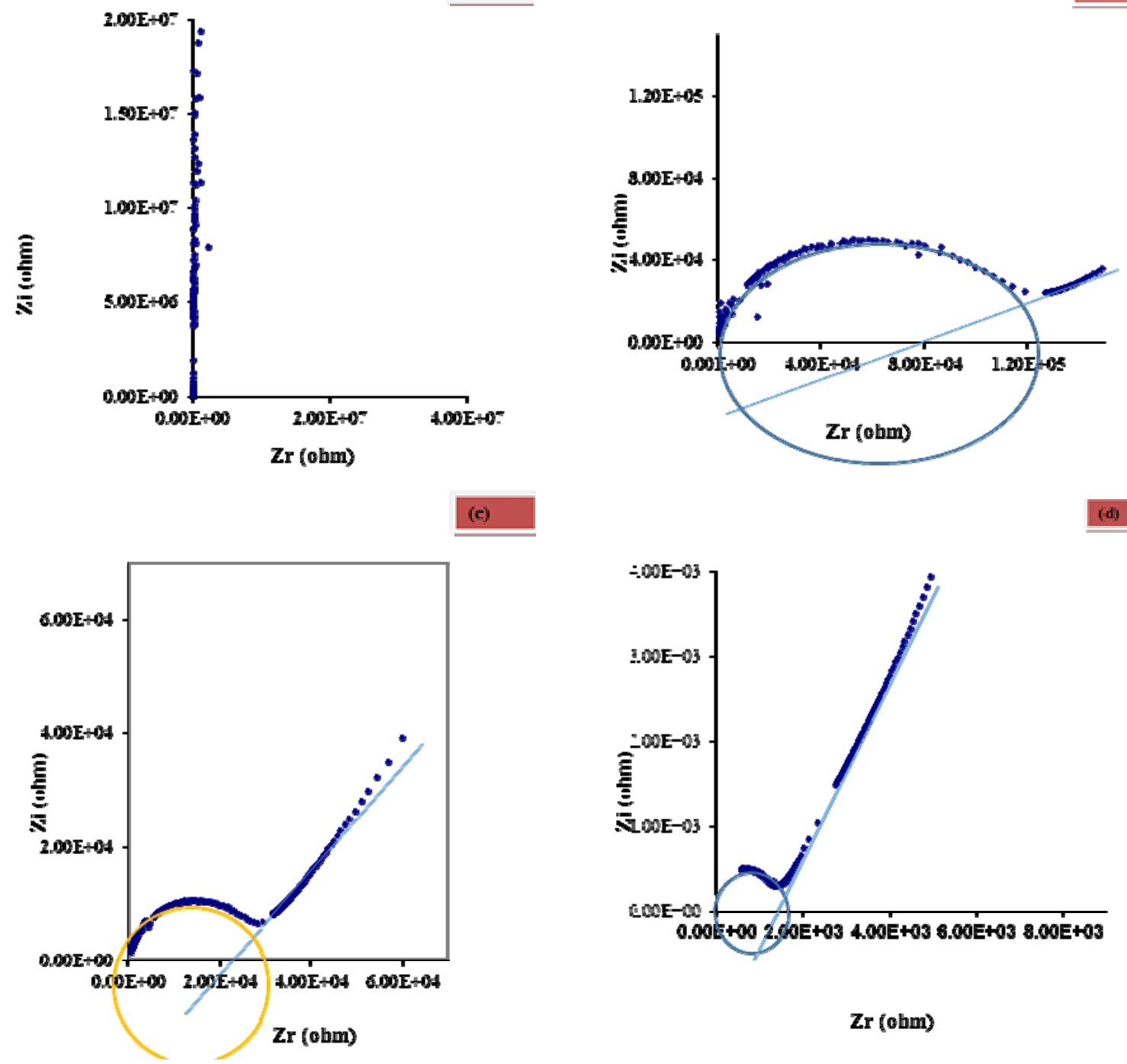

Zr (ohm) 

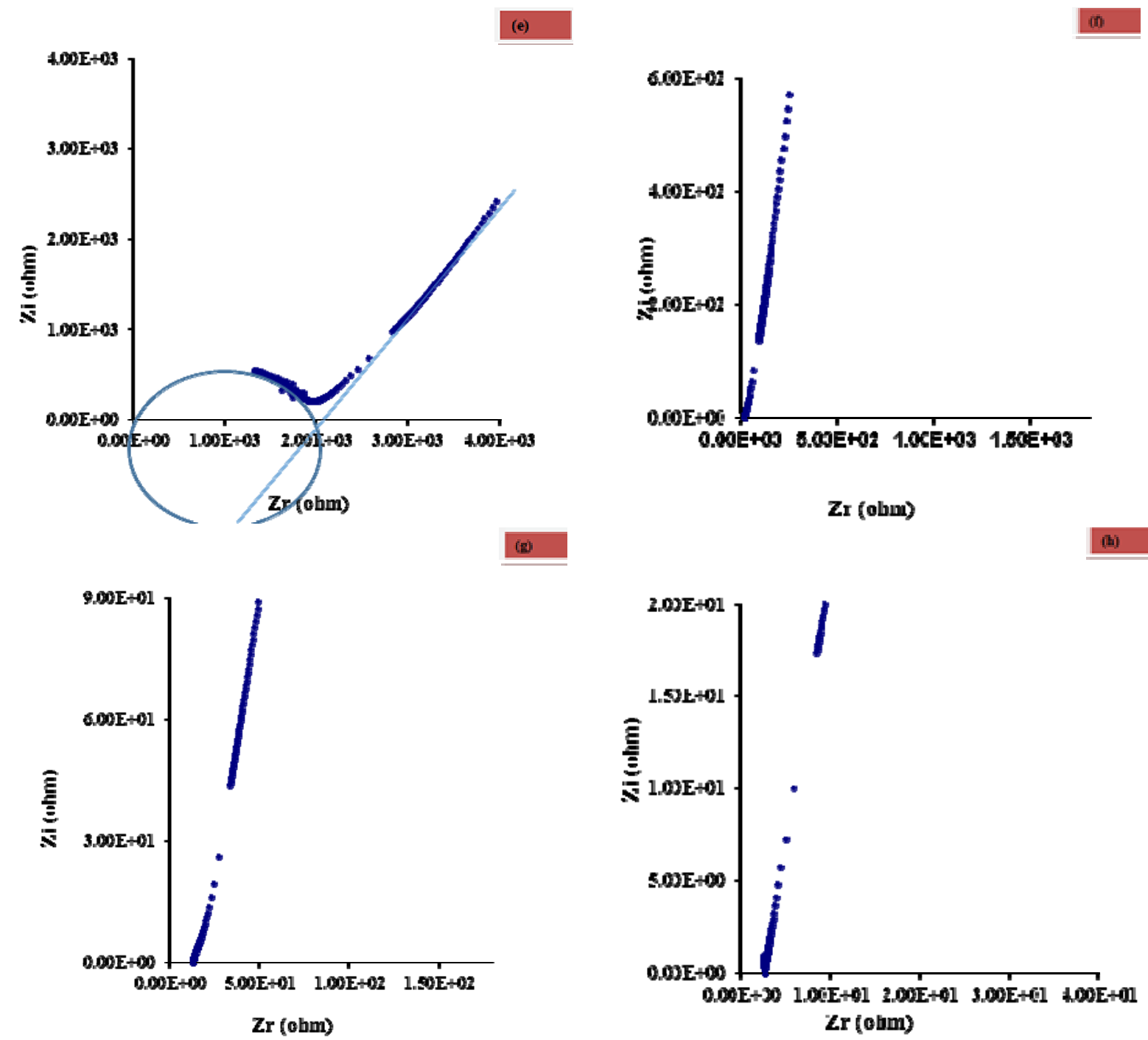

Figure 2. Impedance plots of HSPE containing 0 wt. \% (a); 10 wt. \% (b); 20 wt. \% (c); 30 wt. \% (d); 40 wt. \% (e); 50 wt. $\%$ (f); 60 wt. $\%$ (g); 70 wt. $\%$ (h); the ratio of the $\mathrm{H}_{3} \mathrm{PO}_{4}$ at room temperatures

Table 2. Parameters that Determine the Conductivity in HSPE

\begin{tabular}{ccccc}
\hline Coding & PVA: $\mathrm{H}_{3} \mathrm{PO}_{4}$ & $1(\mathrm{~mm} \pm 0.005)$ & $\mathrm{R}_{\mathrm{b}}(\Omega)$ & $\sigma\left(\mathrm{Scm}^{-1}\right)$ \\
\hline $\mathrm{H} 0$ & $100: 0$ & 0.01385 & $1.15 \times 10^{9}$ & $3.83 \times 10^{-12}$ \\
$\mathrm{H} 10$ & $90: 10$ & 0.01810 & $1.15 \times 10^{6}$ & $1.74 \times 10^{-9}$ \\
$\mathrm{H} 20$ & $80: 20$ & 0.01620 & $1.00 \times 10^{6}$ & $5.16 \times 10^{-9}$ \\
$\mathrm{H} 30$ & $70: 30$ & 0.01730 & $1.50 \times 10^{3}$ & $3.67 \times 10^{-5}$ \\
$\mathrm{H} 40$ & $60: 40$ & 0.02005 & $2.10 \times 10^{3}$ & $3.03 \times 10^{-6}$ \\
$\mathrm{H} 50$ & $50: 50$ & 0.01980 & $4.37 \times 10^{1}$ & $1.47 \times 10^{-4}$ \\
$\mathrm{P} 60$ & $40: 60$ & 0.02000 & $7.37 \times 10^{1}$ & $8.64 \times 10^{-5}$ \\
$\mathrm{H} 70$ & $30: 70$ & 0.30000 & $5.73 \times 10^{0}$ & $1.67 \times 10^{-3}$ \\
\hline
\end{tabular}




\subsection{Crystal Structure Analysis}
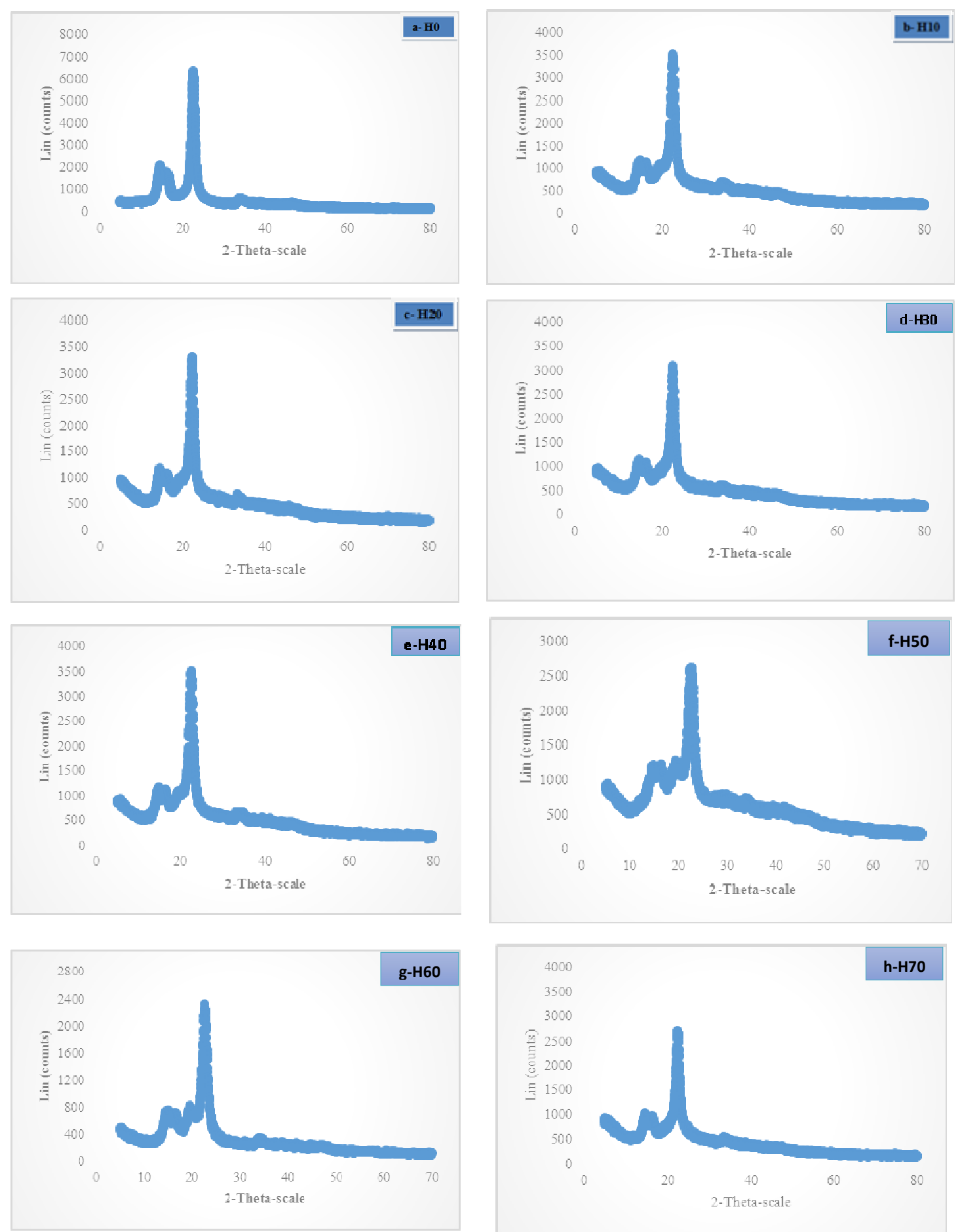

Figure 3. XRD Analysis of HSPE containing 0 wt.\% (a); 10 wt.\% (b); 20 wt.\% (c); 30 wt.\% (d); 40 wt.\% (e); 50 wt.\% (f); 60 wt.\% (g); 70 wt.\% (h) ratio of the $\mathrm{H}_{3} \mathrm{PO}_{4}$

The crystal structure analysis of the solid polymer electrolyte films was examined by a Philip X'Pert X-ray diffractometer (XRD) with $\mathrm{Cu} \mathrm{K}_{\alpha}$ radiation of wavelength $\lambda=1.54056 \AA$ for $2 \theta$ angles between $10^{\circ}$ and $80^{\circ}$. The XRD analysis was carried out on the HSPE films. After the analysis, the following results were obtained. 
The analysis of the structure of the HSPE for 0 wt. \% (a); 10 wt. \% (b); 20 wt. \% (c); 30 wt. \% (d); 40 wt. \% (e); 50 wt. \% (f); 60 wt. \% (g); 70 wt. \% (h) ratio of the $\mathrm{H}_{3} \mathrm{PO}_{4}$ has been shown in Figure 3 (a-h). From the figure it can be observed that the semi-crystalline peak of the PVA was at $\theta=20^{\circ}$ which also affirmed the earlier argument put across by (Hashmi, (c), 2013) about the semi-crystal behavior of the PVA. While the border humps by the left shows the inclusion of the acid and that of polymer.

\subsection{Field Emission Scanning Electron Microscope (FESEM) Analysis}

In this analysis, an ultra-high resolution (UHR) FESEM (SU 8030 a family member of SU 8000; Resolution capability of $1.0 \mathrm{~nm} / 15 \mathrm{kV}, 1.3 \mathrm{~nm} / 1 \mathrm{kV}$ and abling magnification of $80 \mathrm{x}$ to $2,000,000 \mathrm{x}$ ) have been selected. The HSPE films have been examined using different magnifications. The resulting images are shown in Figure 4. In that figure, the FESEM images of HSPE containing 0 wt.\% (i); 10 wt.\% (ii); 20 wt.\% (iii); 30 wt.\% (iv); 40 wt.\% (v); 50 wt.\% (vi); 60 wt.\% (vii); 70 wt.\% (viii) ratio of the $\mathrm{H}_{3} \mathrm{PO}_{4}$ was displayed at three different magnifications; $3.5 \mathrm{~mm} \times 35 \mathrm{k}, 3.5 \mathrm{~mm} \times 150 \mathrm{k}$ and $3.5 \mathrm{~mm} \times 300 \mathrm{k}$ respectively. Overall, the entangling nature of the images indicates the presence of the compositions in the filter paper. And the cited gross changes of the picture from one sample to another, indicates that, the Whatman filter paper soaked in the prepared compositions of the PVA/ $\mathrm{H}_{3} \mathrm{PO}_{4}$ liquid electrolyte was not "well-soaked" as such, the some samples show obvious holes.
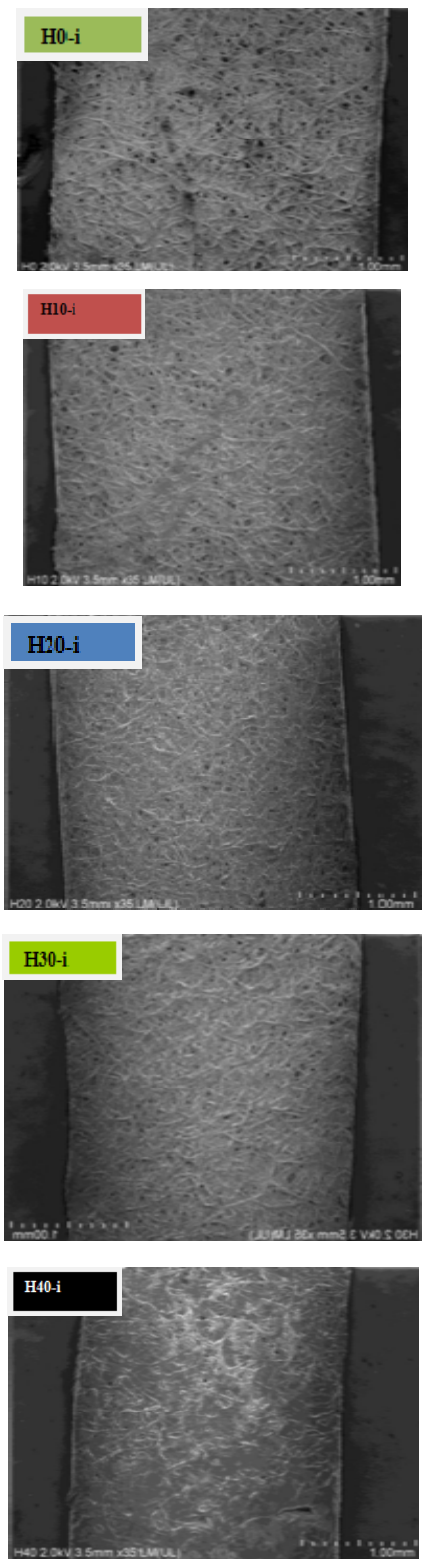
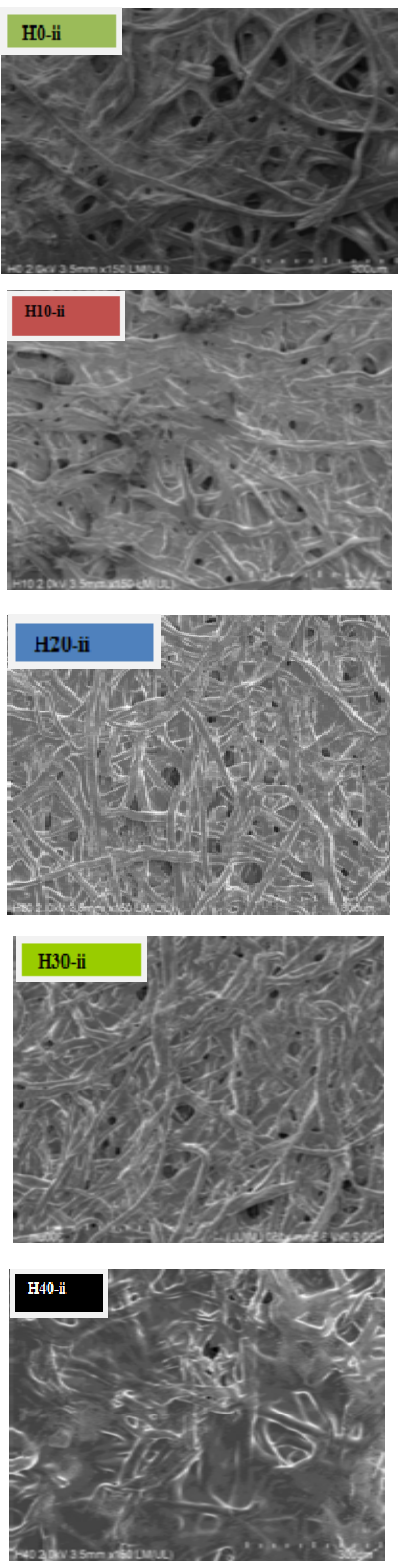
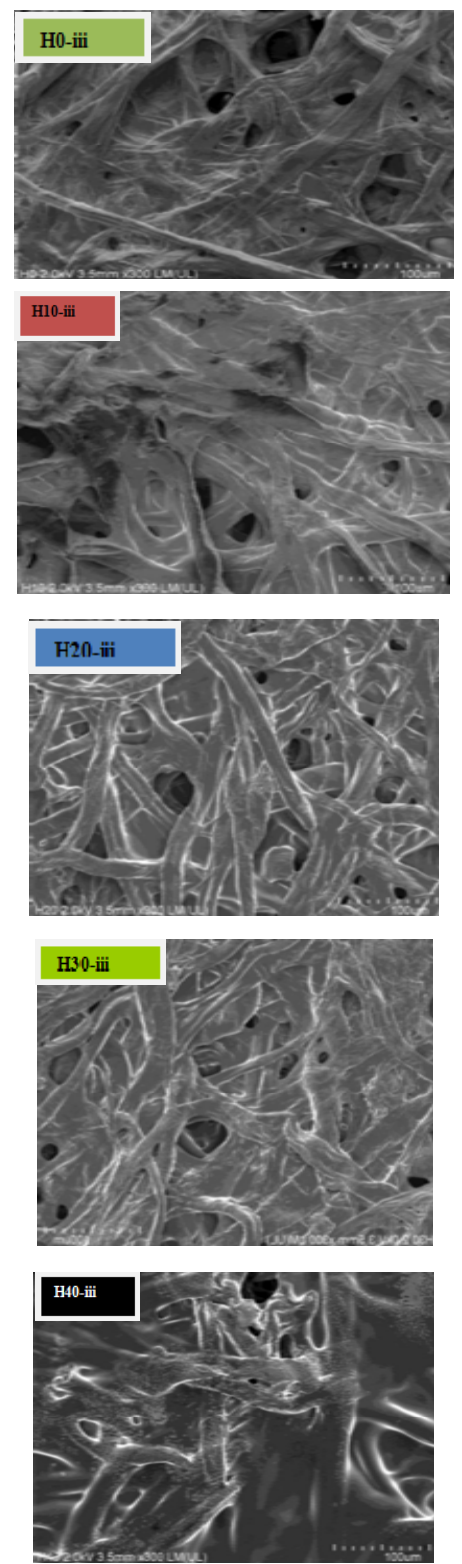

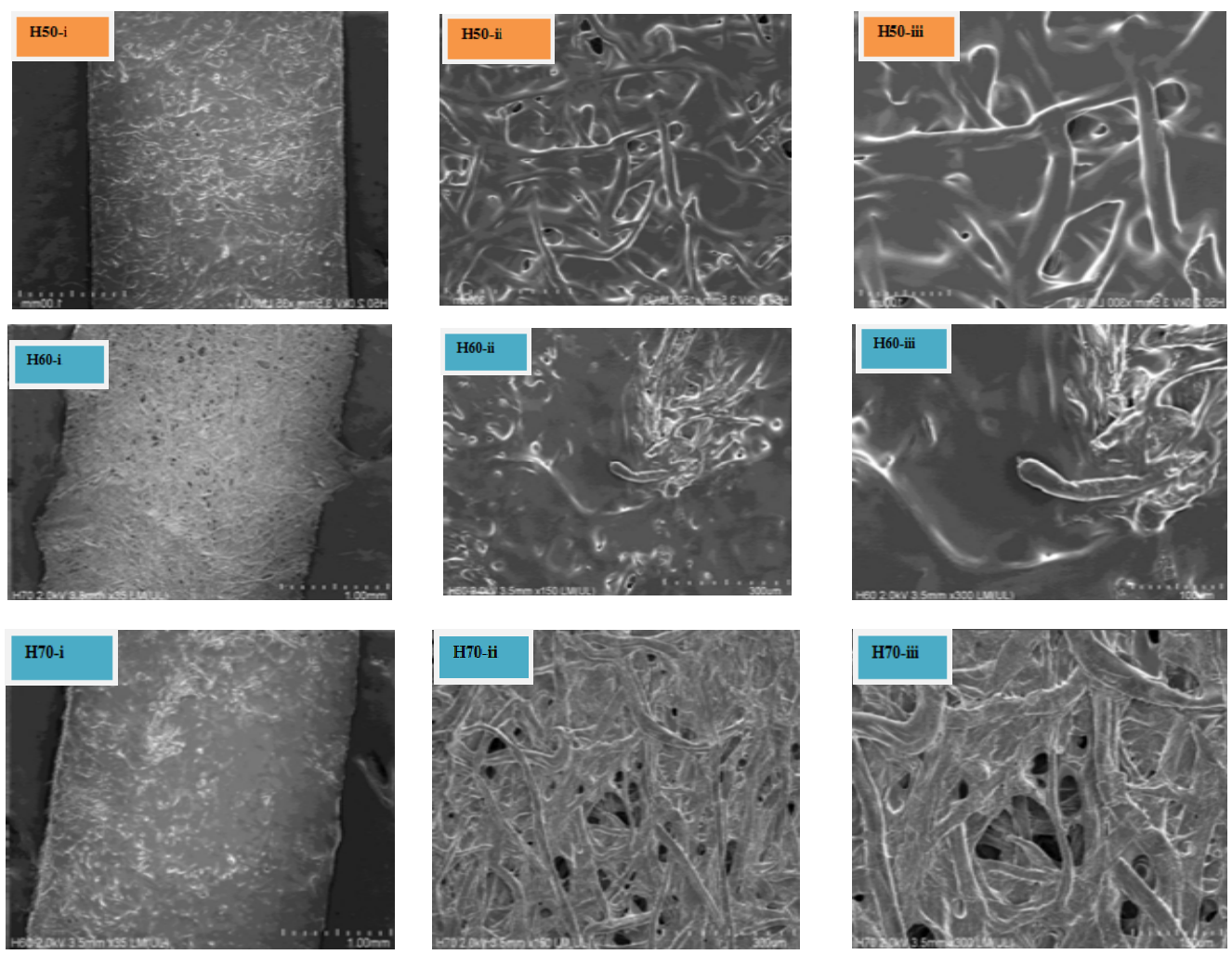

Figure 4. FESEM Images of HSPE containing 0 wt.\% (i); 10 wt.\% (ii); 20 wt.\% (iii); 30 wt.\% (iv); 40 wt.\% (v); 50 wt. \% (vi); 60 wt.\% (vii); 70 wt.\% (viii); ratio of the $\mathrm{H}_{3} \mathrm{PO}_{4}$. The magnification of the images taken were at (i) 3.5 $\mathrm{mm} \times 35 \mathrm{k}$, (ii) $3.5 \mathrm{~mm} \times 150 \mathrm{k}$ and (iii) $3.5 \mathrm{~mm} \times 300 \mathrm{k}$

\subsection{Differential Scanning Calorimetry Analysis}

The DSC thermal analysis was carried out using a Mettler Toledo DSC A851 with Star software under $\mathrm{N}_{2}$ atmosphere with $10{ }^{\circ} \mathrm{C} / \mathrm{min}$ heating rate from 40 to $300{ }^{\circ} \mathrm{C}$ in order to observe the crystalline and semi-crystalline behavior of the whole samples, therefore, various parameters related to thermal properties such as glass transition temperature $\left(\boldsymbol{T}_{g}\right)$, melting temperature $\left(\boldsymbol{T}_{\boldsymbol{m}}\right)$ of crystalline phase of the polymer electrolytes and degree of crystallinity $\left(T_{c}\right)$ can be evaluated from the DSC data and are summarized in Table 3. The samples for DSC measurements were prepared from several tiny rectangular pieces cut from the polymer film to a mass ranging from $7.08-19.82 \mathrm{mg}$ for the HSPE. The temperature range studied was -40 to $200{ }^{\circ} \mathrm{C}$. The heating/cooling rate was $10{ }^{\circ} \mathrm{C} / \mathrm{min}$.

Table 3. Parameters for the Thermometric Analysis in HSPE

\begin{tabular}{lllllr}
\hline & & & \multicolumn{3}{c}{ Temperature $\left({ }^{\circ} \mathrm{C}\right)$} \\
\cline { 4 - 5 } Coding & PVA: ${ }_{3} \mathrm{PO}_{4}$ & Mass $(\mathrm{g})$ & $T_{g}$ & $T_{m}$ & $T_{c}$ \\
\hline $\mathrm{H} 0$ & $100: 0$ & 7.08 & 89.43 & 215.76 & 165.00 \\
$\mathrm{H} 10$ & $90: 10$ & 8.58 & 125.00 & 164.81 & 95.00 \\
$\mathrm{H} 20$ & $80: 20$ & 14.63 & 145.35 & 172.59 & - \\
$\mathrm{H} 30$ & $70: 30$ & 12.08 & 142.85 & 68.34 & - \\
$\mathrm{H} 40$ & $60: 40$ & 12.08 & 119.24 & 159.89 & - \\
$\mathrm{H} 50$ & $50: 50$ & 8.65 & 102.72 & 117.70 & - \\
$\mathrm{H} 60$ & $40: 60$ & 19.82 & 96.80 & 150.24 & - \\
$\mathrm{H} 70$ & $30: 70$ & 8.80 & 84.51 & 111.91 & - \\
\hline
\end{tabular}


Figure 5 shows the DSC analysis result for the HSPE containing 0 wt. \% (a); 10 wt. \% (b); 20 wt. \% (c); 30 wt. \% (d); 40 wt. \% (e); 50 wt. \% (f); 60 wt. \% (g); 70 wt. \%. From that Figure and the Table 3, one can deduce that, only the H0 which has $100 \mathrm{wt}$ \% of PVA immersed with filter paper immerse in it, gave a $T_{m}$ value that is closely related to the theoretical value. Others have been down and upward shifting in terms of the $T_{m}$. Moreover, we were unable to detect the $T_{c}$ for all the samples except in $\mathrm{H} 0$ and H10. However, since the higher the melting point temperature the more the stability of the molecules therein, pure PVA has more stable molecules than $\mathrm{PVA} / \mathrm{H}_{3} \mathrm{PO}$ composite. So, it can be seen that the $T_{m}$ and $T_{c}$ values decreases (or even diminishes) as the concentration of the acid increase. This is as a result of the fact that, in homogenized blends, the melting shifts to the lower level (Othman et al., 2011; Guirguis \& Moselhey, 2012.). Furthermore, the theoretical glass transition of the PVA alone is about $85^{\circ} \mathrm{C}$ while the composite shows down and upwards shifts of this temperature. This could be also be as a result of the gradual increment in the concentration of the acid.
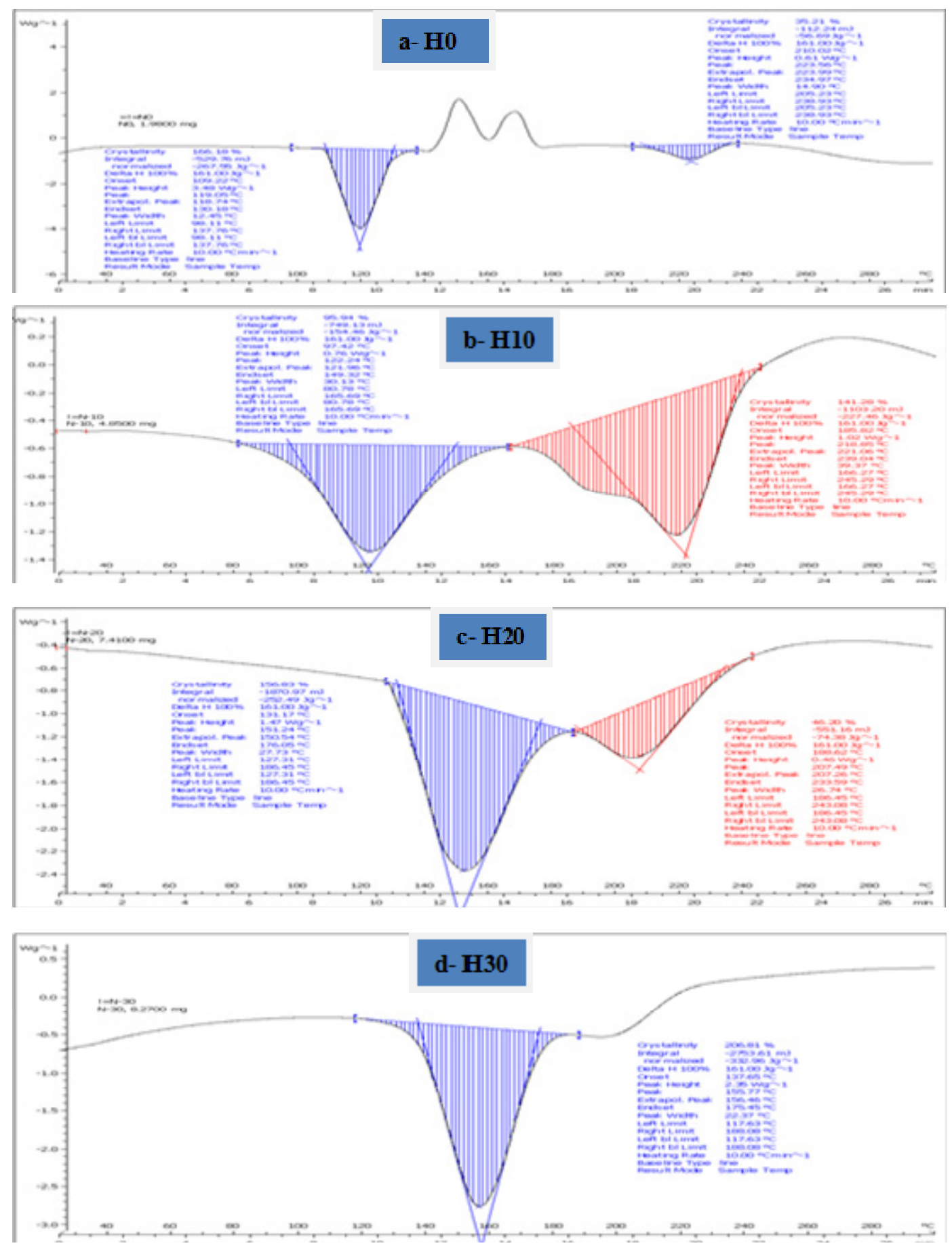

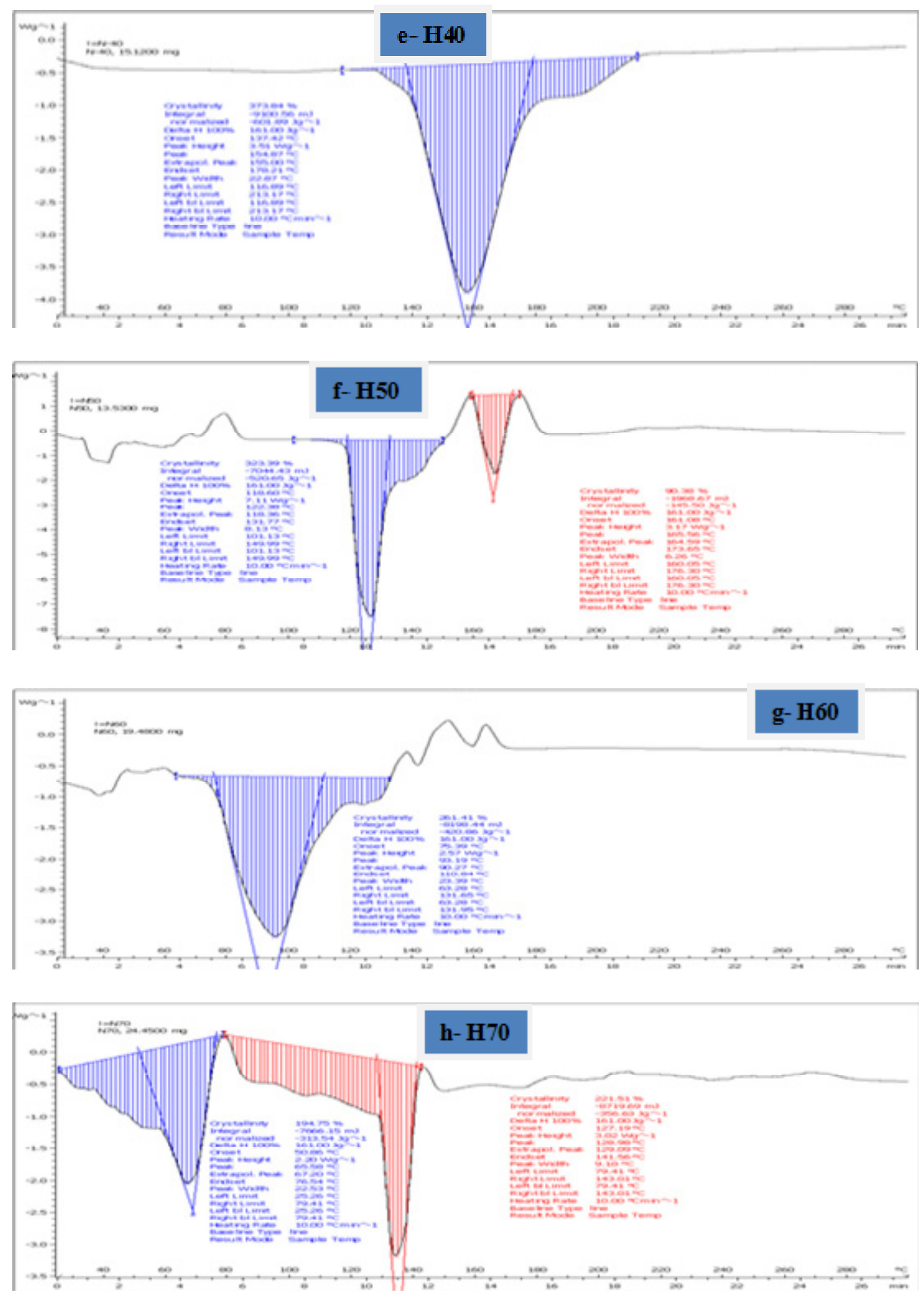

Figure 5. DSC Analysis of HSPE containing 0 wt.\% (a); 10 wt. $\%$ (b); 20 wt.\% (c); 30 wt.\% (d); 40 wt.\% (e); 50 wt.\% (f); 60 wt.\% (g); 70 wt.\% (h)

\section{Conclusion}

The importance of polymer electrolyte in nowadays technology cannot be over emphasized. In this work, we have presented the noble performance of HSPE measured at room temperature and to be used as an electrolyte as well as a separator from the composition of polyvinyl alcohol (PVA) and Phosphoric acid $\left(\mathrm{H}_{3} \mathrm{PO}_{4}\right)$, with, the PVA samples 
kept constant while varying the phosphoric acid at $0,10,20,30,40,50,60$, and $70 \mathrm{wt}$ \% immerse in a filter paper. The HSPE shows an excellent, results in term conductivity studies in that, highest conductivity of $1.67 \times 10^{-3}$. $\mathrm{Scm}^{-1}$ was obtained after the impedance analysis. The XRD analysis reveals the semi-crystalline peak of the PVA at $\theta=20^{\circ}$ border humps of the left indicating the inclusion of the acid and the crystallinity decreases as the acid concentration increases. Which in turns indicate that, there is an enhancement in the amorphicity of the samples responsible for process of ion transport. This characteristic behavior was confirmed from the analysis of the differential scanning calorimetry results. FESEM result pictured the entangling nature of the combined samples as result of the presence of the filter paper.

\section{Acknowledgements}

The corresponding author wishes to acknowledge the assistance and contributions of management of the Faculty of Science and Technology USIM under which ERGS grant (USIM/ERGS-FST-52-50111) has been provided for the purpose of this research.

\section{Reference}

Ahmad Khiar, A. S., \& Arof, A. K. (2010). Conductivity Studies of Starched-based polymer electrolytes. Ionics, 16, 123-129. http://dx.doi.org/ 10.1007/s11581-009-0356-y

Ahmad, A., Rahman, M. Y. B. A., \& Talib, I. A. (2010). Solid polymeric electrolyte of poly (ethylene) oxide- $50 \%$ epoxidized natural rubber-lithium triflate (PEO-ENR50-LiCF3SO3). Natural Science, 2(03), 190-196. http://dx.doi.org/10.4236/ns.2010.23029

Gu, H. B., Kim, J. U., Song, H. W., Park, G. C., \& Park, B. K. (2000). Electrochemical Properties of Carbon Composite Electrode with Polymer Electrolyte for Electric Double-Layer Capacitor. Electrochimica Acta, 45, 1533-1536. http://dx.doi.org/ 10.1016/S0013-4686(99)00370-9

Guirguis, O. W., \& Moselhey, M. T. H. (2012). Thermal and structural studies of poly(vinyl alcohol) and hydroxypropyl cellulose blends. Natural Science, 4, 57-67. http://dx.doi.org/ 10.4236/ns.2012.41009

Hashim, M. A, Sa'adu, L., \& Dasuki, A. K. (2012). Supercapacitor Based On Activated Carbon And Polymer Electrolyte. International Journal Of Sustainable Energy And Environmental Research, 1, 1-6.

Hashim, M. A., Sa'adu, L., Baharuddin, M., \& Dasuki, A. K. (2014). Using PVA, Methacrylate and Lauroyl Chitosan as Separator in Supercapacitors. Journal of Materials Science Research, 3, 1, http://dx.doi.org/ 10.5539/jmsr.v3n1p25

Hashmi, S. A. (2013). Characteristics of Conducting Polymers for their Supercapacitive Performance. Paper presented at the Workshop on Advanced Energy Storage Materials \& Devices (WAESD). Universiti Pertahanan Nasional Malaysia (National Defense University Malaysia).

Hashmi, S. A. (2013). Electrical Double Layer Capacitor: Recent Development. Paper presented at the Workshop on Advanced Energy Storage Materials \& Devices (WAESD). Universiti Pertahanan Nasional Malaysia (National Defense University Malaysia).

Hashmi, S. A. (2013). Polymer-Based Gel electrolytes for New Generation Supercapacitors. Paper presented at the Workshop on Advanced Energy Storage Materials \& Devices (WAESD). Universiti Pertahanan Nasional Malaysia (National Defense University Malaysia).

Jiang, L., Vangari, M., Pryor, T., Xiao, Z., \& Korivi, N. S. (2013). Miniature Supercapacitors Based on Nanocomposite Thin Films". Microelectronic Engineering., 111, 52-57. http://dx.doi.org/10.1016/j.mee. 2013.01.030

Kumar, K. V., \& Suneeta Sundar, G. (2010). Conductivity Studies Of (PEO +KHCO3) Solid Electrolyte System and its Application as an Electrochemical Cell. Journal of Engineering Science and Technology, 5, 130-139.

Kuo, C. W., Huang, C. W., Chen, B. K., Li, W. B., Chen, P. R., Ho, T. H., .. Tzi-Yi, W. (2013). Enhanced Ionic Conductivity in PAN-PEGME-LiClO4-PC Composite Polymer Electrolytes. Int. J. Electrochem. Sci., 8, 3834-3850.

Lim, D. H., Manuel, J., Ahn, J. H., Kim, J. K., Jacobsson, P., Matic, A., ... Kim, K. W. (2012). Polymer Electrolytes Based on Poly(Vinylidene Fluoride-Co-Hexafluoropropylene) Nanofibrous Membranes Containing Polymer Plasticizers for Lithium Batteries. Solid State Ionics, 225, 631-635. http://dx.doi.org/10. 1016/j.ssi.2012.03.028

Othman, N., Azahari, N. A., \& Ismail, H. (2011). Thermal Properties Of Polyvinyl Alcohol (PVOH)/Corn Starch Blend Film. Malaysian Polymer Journal, 6, 147-154. 
Qiu, W. L., Ma, X. H., Yang, Q. H., Fu, Y. B., \& Zong, X. F. (2004). Novel Preparation of Nanocomposite Polymer Electrolyte and its Application to Lithium Polymer Batteries. Journal of Power Sources, 138, 245-252. http://dx.doi.org/10.1016/j.jpowsour.2004.06.061

Ragavendran, K., Kalyani, P., Veluchamy, A., Banumathi, S., Thirunakaran, R., \& Benedict, T. J. (2004). Characterization of Plasticized PEO Based Solid Polymer Electrolyte by XRD and AC Impedance Methods. Portugaliae Electrochimica Acta, 22, 149-159.

Sawada, H., Ariyoshi, Y., Lee, K., Kyokane, J., \& Kawase, T. (2000). New Approach To Highly Conductive Polymer Electrolytes: Synthesis of Gelling Fluoroalkylated End-Capped 2-Acrylamido-2-Methylpropanesulfonic Acid Copolymers Containing Poly(Oxyethylene) Units. European Polymer Journal, 36, 2523-2526. http://dx.doi.org/10.1016/S0014-3057(00)00024-0

Sotta, D., Bernard, J., \& Moynot, V. S. (2010). Application of Electrochemical Impedance Spectroscopy to The Study of Ionic Transport in Polymer-Based Electrolytes. Progress in Organic Coatings, 69, 207-214. http://dx.doi.org/10.1016/j.porgcoat.2010.04.011

Toney, M. F. (1992). X-Ray diffraction. In L. E. Fitzpatrick, C. R. Brundle, C. A. Evans Jr, \& S. Wilson (Comp. \& Ed.), Encyclopedia of Material characterization (pp. 198-213).

Tripathi, S. K., Gupta, A., \& Manju, K. (2012). Studies on Electrical Conductivity and Dielectric Behaviour of PVdF-HFP-PMMA-NaI Polymer Blend Electrolyte. Bull. Mater. Sci., 35, 969-975. http://dx.doi.org/10. 1007/s12034-012-0387-2

Ulaganathan, M., Nithya, R., \& Rajendran, S. (2012). Surface Analysis Studies on Polymer Electrolyte Membranes Using Scanning Electron Microscope and Atomic Force Microscope. Intech, 33, 671-694.

Yang, C. C. (2004). Chemical Composition and XRD Analyses for Alkaline Composite PVA Polymer Electrolyte. Materials Letters, 58, 33-38. http://dx.doi.org/10.1016/S0167-577X(03)00409-9

Yang, R., Zhang, S., Zhang, L., \& Wenbo, L. (2013). Electrical Properties of Composite Polymer Electrolytes Based on PEO-SN-LiCF $\mathrm{SO}_{3}$. Int. J. Electrochem. Sci., 8, 10163-10169.

Zhang, Y. J., Huang, Y. D., \& Lei, W. (2006). Study of EVOH Based Single Ion Polymer Electrolyte: Composition and Microstructure Effects on the Proton Conductivity. Solid State Ionics, 177, 65-71. http://dx.doi.org/10.1016/j.ssi.2005.10.008

\section{Copyrights}

Copyright for this article is retained by the author(s), with first publication rights granted to the journal.

This is an open-access article distributed under the terms and conditions of the Creative Commons Attribution license (http://creativecommons.org/licenses/by/3.0/). 